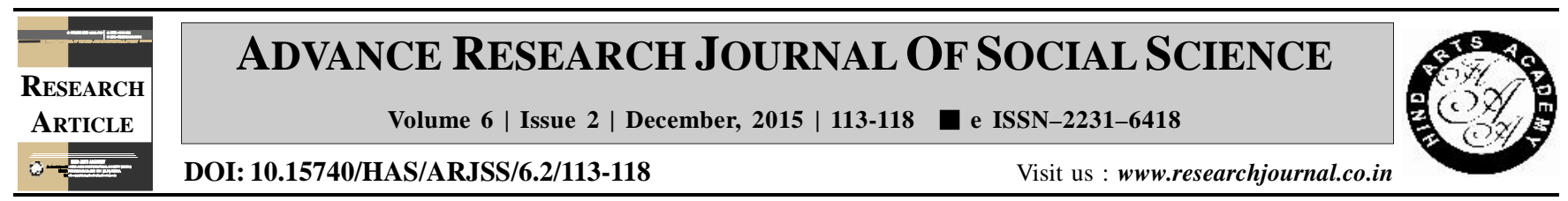

\title{
Use pattern of solar lighting system in rural households
}

Komal* and Savita Singal

Department of Family Resource Management, I.C. College of Home Science, C.C.S. Haryana Agricultural University, HISAR (HARYANA) INDIA

\section{ARTICLE INFO :}

$\begin{array}{lll}\text { Received } & : & 16.07 .2014 \\ \text { Revised } & : & 03.10 .2015 \\ \text { Accepted } & : & 17.10 .2015\end{array}$

KEY WORDS :

Solar energy, Solar light, Use pattern, Awareness

HOW TO CITE THIS ARTICLE :

Komal and Singal, Savita (2015). Use pattern of solar lighting system in rural households. Adv. Res. J. Soc. Sci., 6 (2) : 113-118.

*Author for correspondence

\begin{abstract}
Over the last few decades, India's energy consumption has been increasing at a very fast rate due to population growth and economic development. Due to the increasing demand of energy day by day and depleting sources of conventional energy sources i.e., coal, oil and natural gas, solar energy sources offer viable options to address the energy scarcity of the country. The objective was to study the use pattern of solar technologies in rural areas. The present study was conducted in two villages viz., Ludas and Patan of Hisar block II, district Hisar selected randomly. For collecting the data pertaining to use pattern of solar technologies was collected by using, duly pretested interview schedule. A sample of 100 rural women respondents were taken randomly. A field survey was done to study the use pattern of solar lighting system in rural areas. It observed that respondents belonged to middle aged group (60.00\%), were housewives (87.00\%) and educated upto primary level (28.00\%). Respondents were aware of CFL based solar lighting system (100\%) and solar lantern (85.00\%) but they had only CFL based solar lighting system (83.00\%) and solar lantern (17.00\%). Respondents placed their lights in bed room $(60.71 \%)$ and solar lantern in field $(88.24 \%)$. Respondents used light for $9-10$ months $(87.50 \%)$ and fan for 7-8 months (90.75\%). It can be concluded that respondents were used only solar lighting system and solar lantern. Hence there is a need for the development of awareness about benefits of all type of solar technologies.
\end{abstract}

